\title{
IMPLEMENTATION CRYPTOGRAPHY DATA ENCRYPTION STANDARD (DES) AND TRIPLE DATA ENCRYPTION STANDARD (3DES) METHOD IN COMMUNiCATION SYSTEM BASEd NEAR FiELd COMMUNiCATION (NFC)
}

\author{
Ratnadewi ${ }^{1)}$, Roy Pramono Adhie ${ }^{2)}$, Yonatan Hutama ${ }^{3)}$ \\ ${ }^{1)}$ Electrical Engineering Department, Universitas Kristen Maranatha , Bandung, Indonesia \\ E-mail: ratnadewi.bandung@gmail.com \\ ${ }^{2)}$ Electrical Engineering Department, Universitas Kristen Maranatha , Bandung, Indonesia \\ E-mail: roy.adhie@gmail.com \\ ${ }^{3)}$ Electrical Engineering Department, Universitas Kristen Maranatha , Bandung, Indonesia \\ E-mail: yon_htm@yahoo.com
}

\begin{abstract}
Cryptography is a method used to create secure communication by manipulating sent messages during the communication occurred so only intended party that can know the content of that messages. Some of the most commonly used cryptography methods to protect sent messages, especially in the form of text, are DES and 3DES cryptography method. This research will explain the DES and 3DES cryptography method and its use for stored data security in smart cards that working in the NFC-based communication system.
\end{abstract}

Several things that will be explained in this research is the ways of working of DES and 3DES cryptography method in doing the protection process of a data and software engineering through the creation of application using $\mathrm{C}++$ programming language to realize and test the performance of DES and 3DES cryptography method in encrypted data writing process to smart cards and decrypted data reading process from smart cards.

The execution time of the entering and the reading process data using a smart card DES cryptography method is faster than using 3DES cryptography.

Keywords: Cryptography, Data Encryption Standard (DES), Triple Data Encryption Standard (3DES), NFC 